\title{
Propyl gallate inhibits the growth of endothelial cells, especially calf pulmonary arterial endothelial cells via caspase-independent apoptosis
}

\author{
YONG HWAN HAN ${ }^{1}$, HWA JIN MOON ${ }^{1}$, BO RA YOU ${ }^{1}$, YEON MI YANG ${ }^{2}$, \\ SUNG ZOO KIM ${ }^{1}$, SUHN HEE KIM ${ }^{1}$ and WOO HYUN PARK ${ }^{1}$ \\ ${ }^{1}$ Department of Physiology, Medical School, Centers for Healthcare Technology Development, \\ Institute for Medical Sciences; ${ }^{2}$ Department of Pediatric Dentistry, School of Dentistry, \\ Chonbuk National University, JeonJu 561-180, Republic of Korea
}

Received February 12, 2010; Accepted March 12, 2010

DOI: 10.3892/ijmm_00000425

\begin{abstract}
Propyl gallate (PG) as a synthetic antioxidant exerting a variety of effects on tissue and cell functions. We evaluated the effects of PG on the growth of endothelial cells, especially calf pulmonary artery endothelial cells (CPAEC) in relation to apoptosis. PG dose-dependently inhibited the growth of CPAEC and human umbilical vein endothelial cells (HUVEC) at $24 \mathrm{~h}$. The susceptibility of CPAEC to PG was higher than that of HUVEC. PG induced apoptosis in CPAEC, which was accompanied by the loss of mitochondrial membrane potential (MMP; $\Delta \Psi_{\mathrm{m}}$ ). The tested caspase inhibitors (pan-caspase, caspase-3, -8 or -9 inhibitor) did not rescue CPAEC from PG-induced cell death but instead slightly enhanced the cell death. PG increased reactive oxygen species (ROS) level in CPAEC. The caspase inhibitors did not significantly change the ROS level. Furthermore, PG increased the GSH depleted cell number and decreased GSH
\end{abstract}

Correspondence to: Dr Woo Hyun Park, Department of Physiology, Medical School, Chonbuk National University, JeonJu 561-180, Republic of Korea

E-mail: parkwh71@chonbuk.ac.kr

Abbreviations: PG, propyl gallate; EC, endothelial cells; CPAEC, calf pulmonary arterial endothelial cells; HUVEC, human umbilical vein endothelial cells; ROS, reactive oxygen species; MMP $\left(\Delta \Psi_{\mathrm{m}}\right)$, mitochondrial membrane potential; FBS, fetal bovine serum; MTT, 3-(4,5-dimethylthiazol-2-yl)-2,5-diphenyltetrazolium bromide; PI, propidium iodide; FITC, fluorescein isothiocyanate; Z-VAD-FMK, benzyloxycarbonyl-Val-Ala-Asp-fluoromethylketone; Z-DEVDFMK, benzyloxycarbonyl-Asp-Glu-Val-Asp-fluoromethylketone; Z-IETD-FMK, benzyloxycarbonyl-Ile-Glu-Thr-Asp-fluoromethylketone; Z-LEHD-FMK, benzyloxycarbonyl-Leu-Glu-HisAsp-fluoro-methylketone; $\mathrm{H}_{2}$ DCFDA, 2',7'-dichlorodihydrofluorescein diacetate; DHE, dihydroethidium; GSH, glutathione; CMFDA, 5-chloromethyl-fluorescein diacetate

Key words: propyl gallate, apoptosis, endothelial cells, caspase, reactive oxygen species, glutathione level in CPAEC. The tested caspase inhibitors did not significantly change the number in PG-treated CPAEC. Each caspase inhibitor differently alters GSH levels in CPAEC. In conclusion, PG inhibited the growth of endothelial cells, especially CPAEC via caspase-independent apoptosis. PGinduced CPAEC death was accompanied by ROS increase and GSH depletion.

\section{Introduction}

Propyl gallate (PG, 3,4,5-trihydroxybenzoic acid propyl ester) is used as a synthetic antioxidant in processed food, cosmetics and food packing materials as maximum concentrations of $0.1 \%$, to prevent rancidity and spoilage (1). PG is also used to preserve and stabilize medicinal preparations on the US Food and Drug Administration list (2). Because of its prevalent usage, the potential toxicity of $\mathrm{PG}$ has been investigated in vivo $(3,4)$ and in vitro, to assess various toxicological properties, i.e., mutagenicity (5) and cytogenetic effects (6). Despite the assumed low toxicity of PG, it exerts a variety of effects on tissue and cell functions. Several studies demonstrate the benefits of PG as an antioxidant $(7,8)$ and a chemopreventive agent (9). For instance, PG is an efficient protector of liver cells from lipid peroxidation by oxygen radicals (4). PG also has protective effects against oxidative DNA damage using 8-oxoguanine formation as a marker (8). In contrast, it is reported that PG exerted prooxidant properties $(10,11)$. PG is cytotoxic to isolated rat hepatocytes because it impairs mitochondria, leading to ATP depletion (12). PG inhibits growth of microorganisms by inhibiting respiration and nucleic acid synthesis (13). Controversially, the effects of PG can be enhancing or suppressing on carcinogenesis and mutagenesis $(5,14)$. Antioxidative and cytoprotective properties of PG may change to prooxidative, cytotoxic and genotoxic properties in the presence of $\mathrm{Cu}$ (II) (15). Therefore, in order to clarify the discrepancy between the different effects of PG, further studies need to be performed to re-evaluate its function and safety on cells and tissues.

Vascular endothelium is involved in various regulatory functions such as blood pressure, inflammation and angiogenesis (16). Fundamental to the transition of tumors from a 
latent to malignant state, angiogenesis involving formation of new blood vessels from pre-existing vasculature is a crucial part. The proliferation of endothelium cells (ECs; sprouting) is the early step of angiogenesis. Despite critical roles for vascular ECs in tumor biogenesis and progression, the effects of antioxidant compounds, especially PG on ECs remain relatively poorly understood.

In the present study we evaluated the effects of PG on ECs, especially calf pulmonary artery endothelial cells (CPAEC) in relation to cell growth, death, reactive oxygen species (ROS) and glutathione (GSH).

\section{Materials and methods}

Cell culture. Calf normal pulmonary artery endothelial cells (CPAEC) from KCLB (Korean Cell Line Bank) and primary human umbilical vein endothelial cells (HUVEC) from PromoCell GmbH (Heidelberg, Germany) were maintained in humidified incubator containing $5 \% \mathrm{CO}_{2}$ at $37^{\circ} \mathrm{C}$. CPAEC were cultured in RPMI-1640 supplemented with $10 \%$ fetal bovine serum (FBS) and 1\% penicillin-streptomycin (Gibco BRL, Grand Island, NY). CPAEC were routinely grown in 100-mm plastic tissue culture dishes (Nunc, Roskilde, Denmark) and harvested with a solution of trypsin-EDTA (Gibco BRL) while in a logarithmic phase of growth. CPAEC were maintained in these culture conditions for all experiments. HUVEC were cultured in complete endothelial cell growth medium (ECGM, PromoCell) with 2\% FBS. HUVEC were washed and detached with HepesBSS (30 mM Hepes), trypsinEDTA and trypsin neutralization solution (Promocell). HUVEC were used between passages four and six.

Reagents. PG was purchased from the Sigma-Aldrich Chemical Company (St. Louis, MO). PG was dissolved in ethanol at $200 \mathrm{mM}$ as a stock solution. The pan-caspase inhibitor (Z-VAD-FMK, benzyloxycarbonyl-Val-Ala-Asp-fluoromethylketone), caspase-3 inhibitor (Z-DEVD-FMK, benzyloxycarbonyl-Asp-Glu-Val-Asp-fluoromethylketone), caspase8 inhibitor (Z-IETD-FMK, benzyloxycarbonyl-Ile-Glu-ThrAsp-fluoromethylketone) and caspase-9 inhibitor (ZLEHD-FMK, benzyloxycarbonyl-Leu-Glu-His-Asp-fluoromethylketone) were obtained from R\&D Systems, Inc. (Minneapolis, MN) and were dissolved in DMSO (Sigma) at $10 \mathrm{mM}$ as a stock solution. Cells were pretreated with caspase inhibitor for $1 \mathrm{~h}$ prior to treatment with PG. Ethanol $(0.2 \%)$ and DMSO $(0.3 \%)$ were used as a control vehicle. All stock solutions were wrapped in foil and kept at $-20^{\circ} \mathrm{C}$.

Cell growth assay. The effect of drugs on endothelial cell numbers and growth was determined by trypan blue cell counting or measuring 3-(4,5-dimethylthiazol-2-yl)-2,5diphenyltetrazolium bromide (MTT) dye absorbance of living cells as previously described (17). In brief, $1 \times 10^{5}$ cells per well were seeded in 24-well plates (Nunc) for cell counting, and cells $3 \times 10^{4}$ cells per well were seeded in 96well microtiter plates for an MTT assay. After exposure to doses of 50-800 $\mu \mathrm{M}$ PG for $24 \mathrm{~h}$, cells in 24-well plates or 96-well plates were collected with trypsin digestion for trypan blue exclusion cell counting or for an MTT assay. MTT (20 $\mu \mathrm{l})$ (Sigma) solution (2 $\mathrm{mg} / \mathrm{ml}$ in PBS) were added to each well of 96-well plates. The plates were incubated for 4 additional hours at $37^{\circ} \mathrm{C}$. MTT solution in the medium was aspirated off and $200 \mu 1$ of DMSO were added to each well to solubilize the formazan crystals formed in viable cells. Optical density was measured at $570 \mathrm{~nm}$ using a microplate reader (Spectra MAX 340, Molecular Devices Co., Sunnyvale, CA). Each plate contained multiple wells at a given experimental condition and multiple control wells. This procedure was replicated for 2 to 4 plates per condition.

Sub-G1 cell analysis. Sub-G1 cells were determined by propidium iodide (PI, Sigma-Aldrich; Ex/Em=488/617 nm) staining as previously described (18). PI is a fluorescent biomolecule that can be used to stain DNA. In brief, $1 \times 10^{6}$ cells in 60-mm culture dish (Nunc) were incubated with the indicated amounts of PG with or without $15 \mu \mathrm{M}$ each caspase inhibitor for $24 \mathrm{~h}$. Cells were then washed with PBS and fixed in 70\% ethanol. Cells were washed again with PBS, then incubated with PI $(10 \mu \mathrm{g} / \mathrm{ml})$ with simultaneous RNase treatment at $37^{\circ} \mathrm{C}$ for 30 min. Cell DNA content was measured using a FACStar flow cytometer (Becton Dickinson, San Jose, CA) and analyzed using Lysis II and CellFIT software (Becton Dickinson) or ModFit software (Verity Software House, Inc., ME).

Annexin $V$ staining. Apoptosis was determined by staining cells with annexin V-fluorescein isothiocyanate (FITC) $(\mathrm{Ex} / \mathrm{Em}=488 / 519 \mathrm{~nm})$ as previously described (19). In brief, $1 \times 10^{6}$ cells in $60-\mathrm{mm}$ culture dish (Nunc) were incubated with the indicated amounts of PG with or without $15 \mu \mathrm{M}$ each caspase inhibitor for $24 \mathrm{~h}$. Cells were washed twice with cold PBS and then resuspended in $500 \mu \mathrm{l}$ of binding buffer $(10 \mathrm{mM}$ HEPES/NaOH pH 7.4, $140 \mathrm{mM} \mathrm{NaCl}, 2.5 \mathrm{mM} \mathrm{CaCl}_{2}$ ) at a concentration of $1 \times 10^{6}$ cells $/ \mathrm{ml}$. Annexin V-FITC (5 $\left.\mu \mathrm{l}\right)$ (PharMingen, San Diego, CA) was then added to these cells, which were analyzed with a FACStar flow cytometer (Becton Dickinson).

DNA extraction and agarose gel electrophoresis. DNA fragmentation was determined using a commercial kit (Quick Apoptotic DNA ladder detection kit, BioVision, CA). In brief, $1 \times 10^{6}$ cells in 60-mm culture dish (Nunc) were incubated with or without $800 \mu \mathrm{M}$ PG for $24 \mathrm{~h}$. Cells were lysed in $35 \mu \mathrm{l}$ TE Lysis butter, incubated with $5 \mu 1$ Enzyme A solution at $37^{\circ} \mathrm{C}$ for $10 \mathrm{~min}$, and then incubated with $5 \mu \mathrm{l}$ Enzyme B solution at $50^{\circ} \mathrm{C}$ for $30 \mathrm{~min}$. DNA was then precipitated with isopropanol and resuspended in $30 \mu 1$ DNA suspension buffer. DNA were electrophoresed in Tris-borate buffer on $1.2 \%$ agarose gel and stained with ethidium bromide.

Measurement of mitochondrial membrane potential (MMP) $\left(\Delta \Psi_{m}\right)$. MMP $\left(\Delta \Psi_{\mathrm{m}}\right)$ levels were measured by the Rhodamine 123 fluorescent dye $(E x / E m=485 / 535 \mathrm{~nm})$, as previously described (20). In brief, $1 \times 10^{6}$ cells in $60-\mathrm{mm}$ culture dish (Nunc) were incubated with the indicated amounts of PG with or without $15 \mu \mathrm{M}$ each caspase inhibitor for $24 \mathrm{~h}$. Cells were washed twice with PBS and incubated with Rhodamine 123 $\left(0.1 \mu \mathrm{g} / \mathrm{ml}\right.$; Sigma) at $37^{\circ} \mathrm{C}$ for $30 \mathrm{~min}$. Rhodamine 123 staining intensity was determined by flow cytometry. Rhodamine 123 negative cells indicate the loss of MMP $\left(\Delta \Psi_{\mathrm{m}}\right)$ in CPAEC. MMP $\left(\Delta \Psi_{\mathrm{m}}\right)$ levels in cells except MMP 

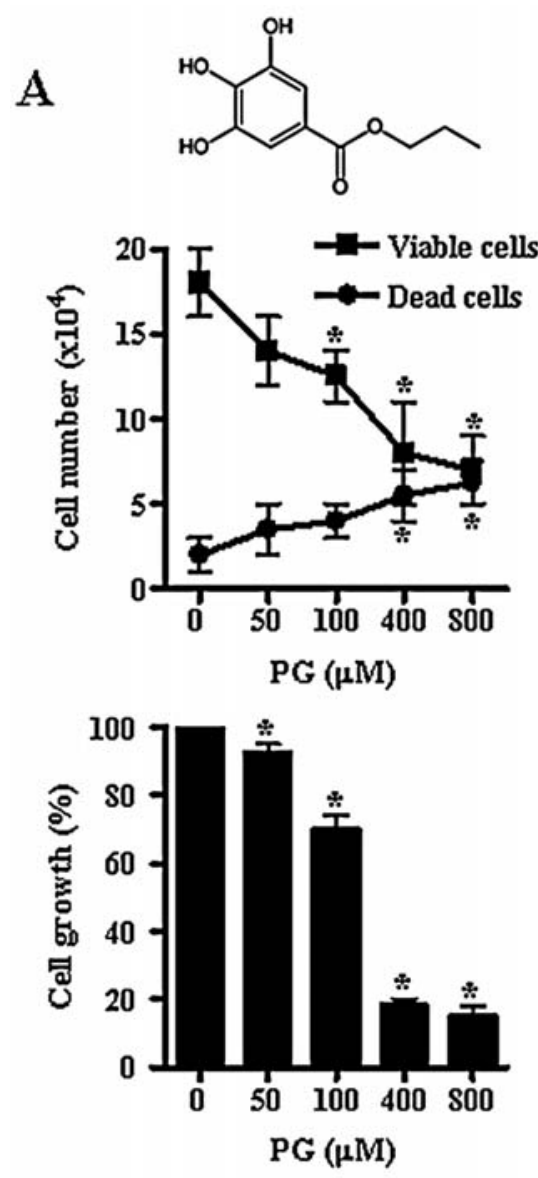

CPAEC
B
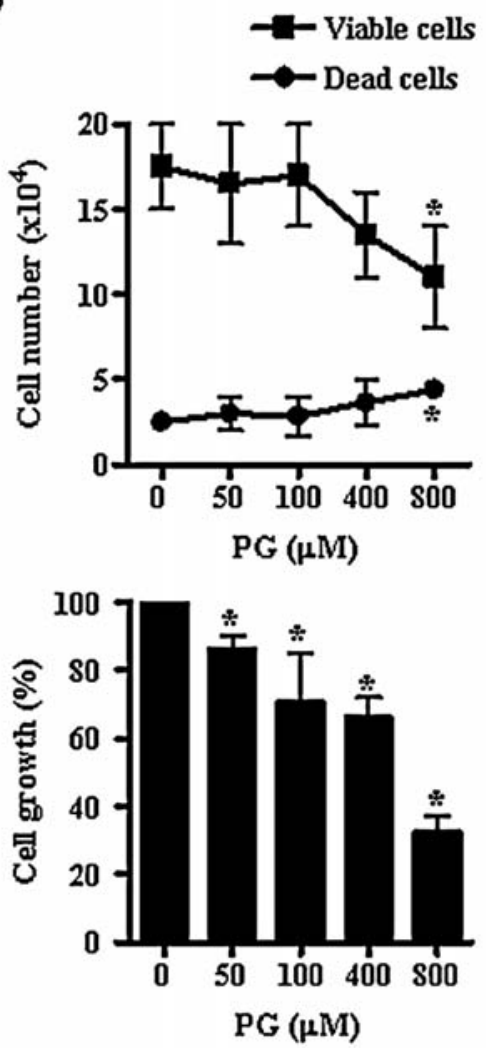

HUVEC

Figure 1. Effects of PG on the growth of CPAEC and HUVEC in vitro. Exponentially-growing cells were treated with the indicated concentrations of PG for $24 \mathrm{~h}$. Cell number and cell growth were assessed by trypan blue exclusion cell counting and an MTT assay, respectively. (A) Structure of propyl gallate (PG) and CPAEC. (B) HUVEC. ${ }^{*} \mathrm{P}<0.05$ compared with the PG-untreated control cell group.

$\left(\Delta \Psi_{\mathrm{m}}\right)$ loss cells were expressed as mean fluorescence intensity (MFI), which was calculated by CellQuest software.

Detection of intracellular ROS and $\mathrm{O}_{2}{ }^{\bullet-}$ levels. Intracellular ROS such as $\mathrm{H}_{2} \mathrm{O}_{2},{ }^{\bullet} \mathrm{OH}$ and $\mathrm{ONOO} \bullet$ were detected by means of an oxidation-sensitive fluorescent probe dye, 2',7'Dichlorodihydrofluorescein diacetate $\left(\mathrm{H}_{2}\right.$ DCFDA; Ex/ $\mathrm{Em}=495 / 529 \mathrm{~nm}$ ) (21) (Invitrogen Molecular Probes, Eugene, OR). $\mathrm{H}_{2}$ DCFDA is poorly selective for $\mathrm{O}_{2}{ }^{\bullet}$. In contrast, dihydroethidium (DHE) $(\mathrm{Ex} / \mathrm{Em}=518 / 605 \mathrm{~nm})$ (Invitrogen Molecular Probes) is highly selective for $\mathrm{O}_{2}{ }^{\bullet-}$ among ROS. In brief, $1 \times 10^{6}$ cells in $60-\mathrm{mm}$ culture dish (Nunc) were incubated with $400 \mu \mathrm{M}$ PG with or without $15 \mu \mathrm{M}$ each caspase inhibitor for $24 \mathrm{~h}$. Cells were then washed in PBS and incubated with $20 \mu \mathrm{M} \mathrm{H}_{2}$ DCFDA or DHE at $37^{\circ} \mathrm{C}$ for $30 \mathrm{~min}$ according to the manufacturers instructions. DCF and DHE fluorescences were detected using a FACStar flow cytometer (Becton Dickinson). ROS and $\mathrm{O}_{2}{ }^{\bullet-}$ levels were expressed as mean fluorescence intensity (MFI), which was calculated by CellQuest software.

Detection of the intracellular glutathione (GSH). Cellular GSH levels were analyzed using 5-chloromethylfluorescein diacetate (CMFDA, Molecular Probes) $(\mathrm{Ex} / \mathrm{Em}=522 / 595 \mathrm{~nm})$ as previously described (21). In brief, $1 \times 10^{6}$ cells in $60-\mathrm{mm}$ culture dish (Nunc) were incubated with $400 \mu \mathrm{M}$ PG with or without $15 \mu \mathrm{M}$ each caspase inhibitor for $24 \mathrm{~h}$. Cells were then washed with PBS and incubated with $5 \mu \mathrm{M}$ CMFDA at $37^{\circ} \mathrm{C}$ for $30 \mathrm{~min}$. CMF fluorescence intensity was determined using a FACStar flow cytometer (Becton Dickinson). Negatively CMF staining (GSH depleted) cells were expressed as the percent of (-) CMF cells. CMF levels in cells except GSH depleted cells were expressed as mean fluorescence intensity (MFI), which was calculated by CellQuest software.

Statistical analysis. The results shown in the figures represent the mean of at least three independent experiments; bar, SD. The data were analyzed using Instat software (GraphPad Prism4, San Diego, CA). The Student's t-test or one-way analysis of variance (ANOVA) with post hoc analysis using Tukey's multiple comparison test was used for parametric data. The statistical significance was defined as $\mathrm{P}<0.05$.

\section{Results}

Effects of PG on the growth of CPAEC and HUVEC. We examined the effect of PG on the growth of CPAEC and HUVEC by trypan blue cell counting. Treatment with 50-800 $\mu \mathrm{M}$ PG significantly decreased the population of 

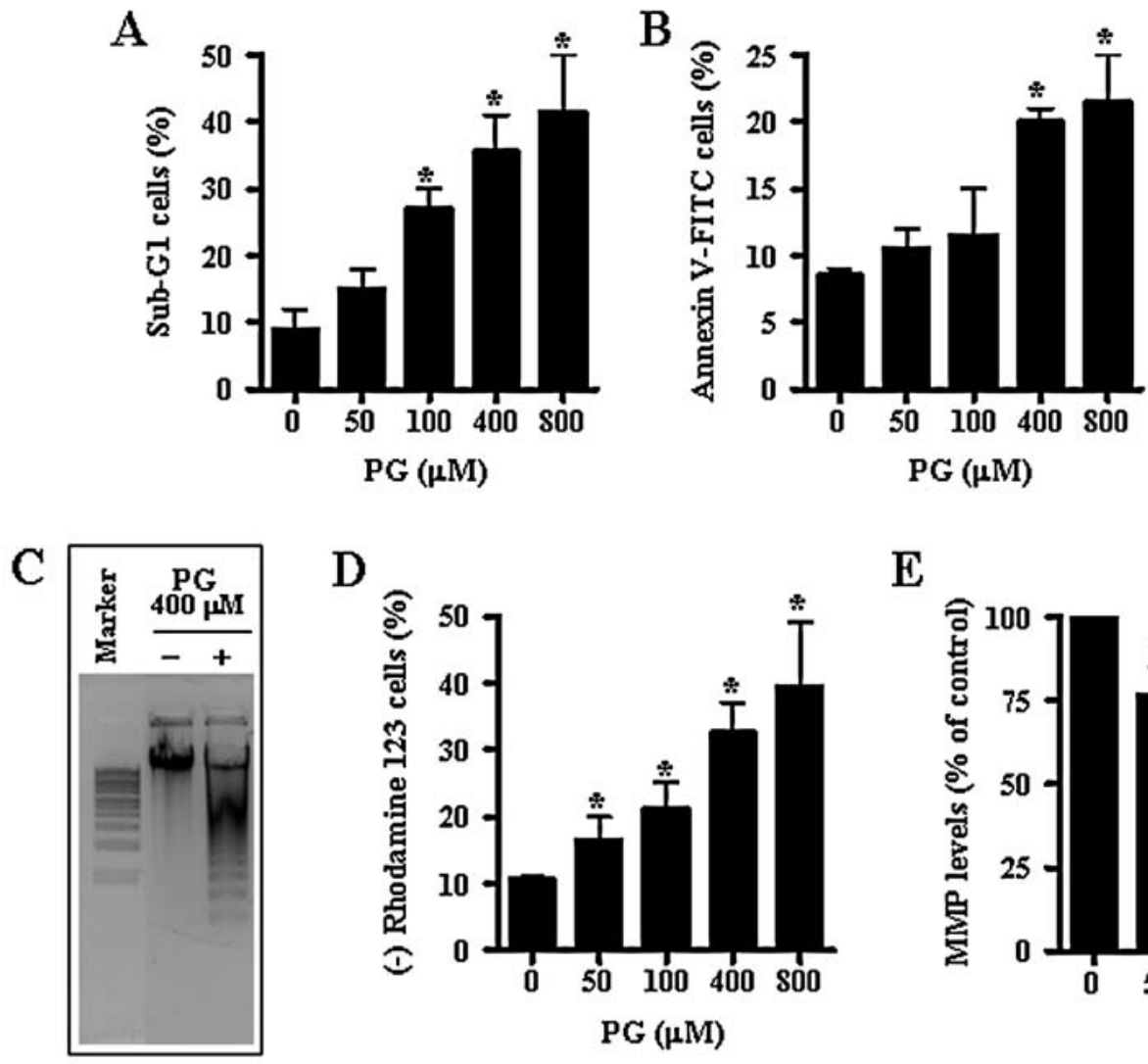

D
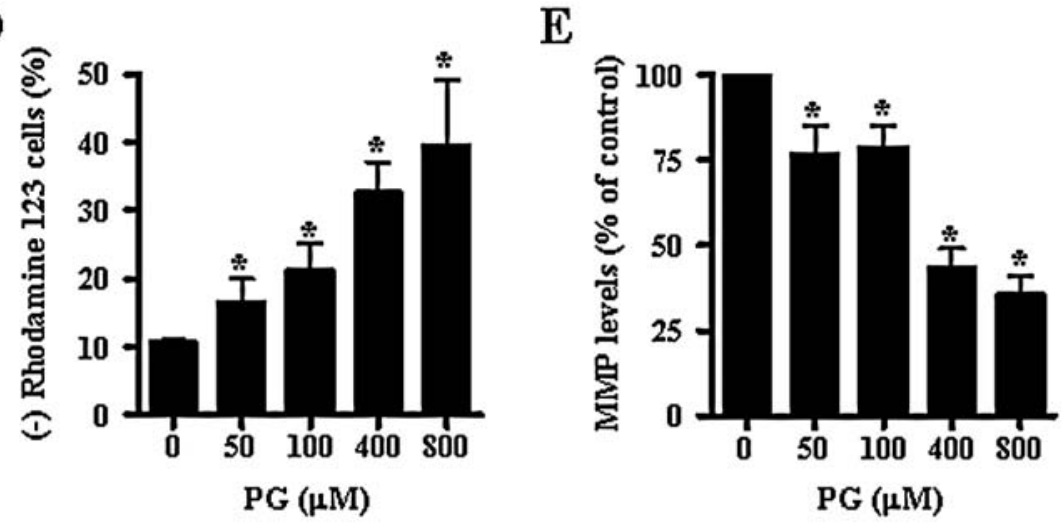

Figure 2. Effects of PG on apoptosis and MMP $\left(\Delta \Psi_{\mathrm{m}}\right)$ in CPAEC. Exponentially-growing cells were treated with the indicated concentrations of PG for $24 \mathrm{~h}$. (A and B) Graphs show the percents of sub-G1 cells (A) and annexin V-positive cells (B). (C) Analysis of DNA fragmentation patterns by 1.2\% agarose gel electrophoresis. (D and E) The graphs show the percent of Rhodamine 123-negative [MMP $\left(\Delta \Psi_{\mathrm{m}}\right)$ loss] cells (D) and MMP ( $\left.\Delta \Psi_{\mathrm{m}}\right)$ levels $(\%)$ compared with control CPAEC (E). ${ }^{*} \mathrm{P}<0.05$ compared with the PG-untreated control group.

viable (trypan blue negative) CPAEC at $24 \mathrm{~h}$ in a dosedependent manner (Fig. 1A). However, only the dose of $800 \mu \mathrm{M}$ PG reduced viable cell numbers of HUVEC at the same time (Fig. 1B). The dead (trypan blue positive) cell numbers of CPAEC and HUVEC dose-dependently increased (Fig. 1A and B). The dead cell number was higher in CPAEC. Collectively, the ratio of dead cells to viable cells was increased in both cell types. When the growth of CPAEC and HUVEC after treatment with PG was also assessed by an MTT assay, dose-dependent reduction of cell growth was observed in both cells with an $\mathrm{IC}_{50}$ of $\sim 100-400 \mu \mathrm{M}$ and $400-800 \mu$ M PG at $24 \mathrm{~h}$, respectively (Fig. 1A and B).

Effects of $P G$ on apoptosis and $M M P\left(\triangle \Psi_{m}\right)$ in CPAEC. We determined whether PG induces apoptosis in CPAEC. As shown in Fig. 2A, the proportion of sub-G1 DNA content cells in PG-treated CPAEC was increased in a dose-dependent manner. The number of annexin $\mathrm{V}$-staining cells was also increased (Fig. 2B). Furthermore, we observed that PG induced nucleosomal DNA fragmentation, which is a hallmark of apoptosis in mammalian cells, in CPAEC (Fig. 2C). These data imply that PG-induced CPAEC death occurred via apoptosis.

Next, we elucidated the effect of PG on MMP $\left(\Delta \Psi_{\mathrm{m}}\right)$ using Rhodamine 123. Treatment with PG induced the loss of MMP $\left(\Delta \Psi_{\mathrm{m}}\right)$ in CPAEC in a dose-dependent manner (Fig. 2D).
Following exposure to $400 \mu \mathrm{M}$ PG for $24 \mathrm{~h}$, the percent of MMP $\left(\Delta \Psi_{\mathrm{m}}\right)$ loss cells was increased $\sim 20 \%$ compared with that of PG-untreated control cells (Fig. 2D). In relation to MMP $\left(\Delta \Psi_{\mathrm{m}}\right)$ levels in cells except Rhodamine 123 negative cells, PG reduced MMP $\left(\Delta \Psi_{\mathrm{m}}\right)$ level in CPAEC (Fig. 2E). Treatment with $400 \mu \mathrm{M}$ PG decreased the level $\sim 60 \%$ (Fig. 2E). The dramatic decrease in MMP $\left(\Delta \Psi_{\mathrm{m}}\right)$ levels was observed at doses $>100 \mu \mathrm{M}$ PG-treated cells (Fig. 2E).

Effects of caspase inhibitors on cell growth and $P G$-treated $C P A E C$. To determine which caspase is involved in the growth inhibition and apoptosis of CPAEC by PG, cells were pretreated with pan-caspase inhibitor (Z-VAD-FMK), caspase-3 inhibitor (Z-DEVD-FMK), caspase-8 inhibitor (Z-IETD-FMK) or caspase-9 inhibitor (Z-LEHD-FMK) at a concentration of $15 \mu \mathrm{M}$ before $400 \mathrm{PG} \mu \mathrm{M}$ treatment, which concentration was considered as a suitable dose to differentiate the levels of cell growth inhibition and death in the presence or absence of each caspase inhibitor. None of the caspase inhibitors including pan-caspase inhibitor significantly affected the growth of PG-treated CPAEC at $24 \mathrm{~h}$, as measured by an MTT assay (Fig. 3A). All of them slightly reduced the growth of PG-treated CPAEC (Fig. 3A). They also slightly increased the population of sub-G1 cells in PG-treated CPAEC but mildly reduced the numbers of PG-untreated control CPAEC (Fig. 3B). Treatment with pan-caspase, caspase-3 and 
A

B
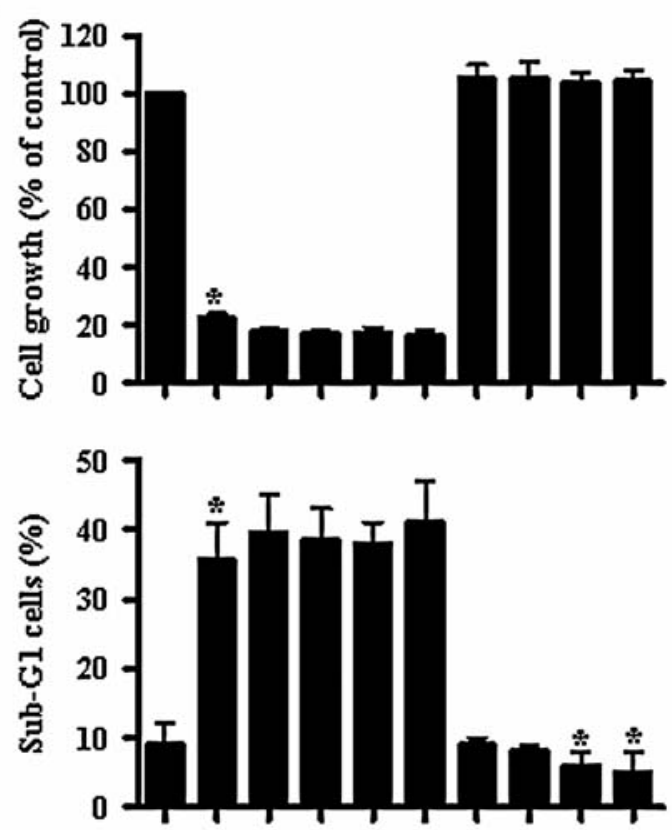

$\mathrm{C}$

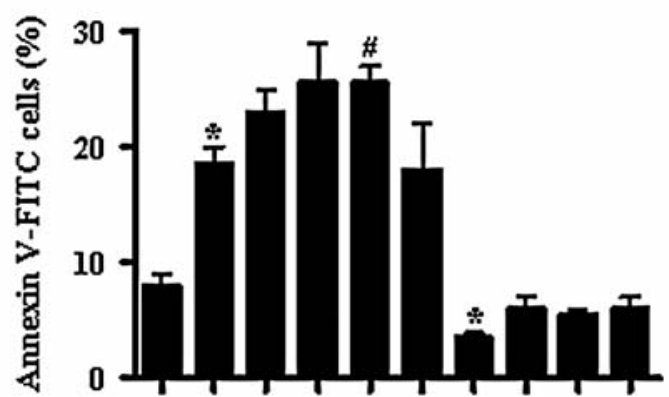

PG $400 \mu \mathrm{M}:-+++++--$ -

ZVAD : - - + - - - + - - -

ZDEVD : - - $-++-\quad-++-$

ZIETD : - - - - + - - - + -

ZLEHD : - $\quad-\quad-\quad-\quad+\quad-\quad-\quad+$

Figure 3. Effects of caspase inhibitors on the cell growth and apoptosis in PG-treated CPAEC. Exponentially-growing cells were treated with $400 \mu \mathrm{M}$ PG and/or each caspase inhibitor $(15 \mu \mathrm{M})$ for $24 \mathrm{~h}$. (A) Graph shows the cell growth, as assessed by an MTT assay. (B and C) Graphs show the percent of sub-G1 cells (B) and annexin V staining cells (C). ${ }^{*} \mathrm{P}<0.05$ compared with the control group. ${ }^{\#} \mathrm{P}<0.05$ compared with cells treated with PG only. Z-VAD, pan-caspase inhibitor; Z-DEVD, caspase-3 inhibitor; Z-IETD, caspase-8 inhibitor; Z-LEHD, caspase-9 inhibitor.

caspase-8 inhibitors increased annexin V-FITC positive cell numbers in PG-treated CPAEC. All the inhibitors reduced basal annexin $\mathrm{V}$ staining cells in control CPAEC (Fig. 3C).

In relation to MMP $\left(\Delta \Psi_{\mathrm{m}}\right)$ in CPAEC, all the inhibitors slightly enhanced the loss of MMP $\left(\Delta \Psi_{\mathrm{m}}\right)$ induced by PG (Fig. 4A). However, they reduced the percent of basal MMP $\left(\Delta \Psi_{\mathrm{m}}\right)$ loss in control CPAEC (Fig. 4A). All the caspase inhibitors except Z-VAD inhibitor slightly reduced MMP $\left(\Delta \Psi_{\mathrm{m}}\right)$ levels in PG-treated CPAEC (Fig. 4B).

Effects of caspase inhibitors on ROS and GSH levels in PGtreated CPAEC. We assessed the changes of the intracellular ROS levels in PG and/or each caspase inhibitor-treated
A

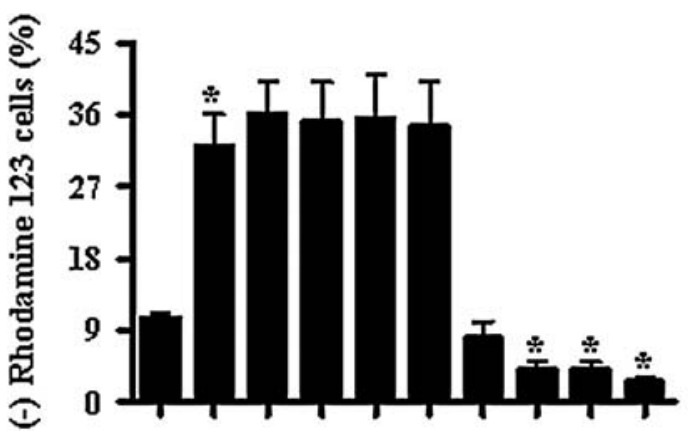

B

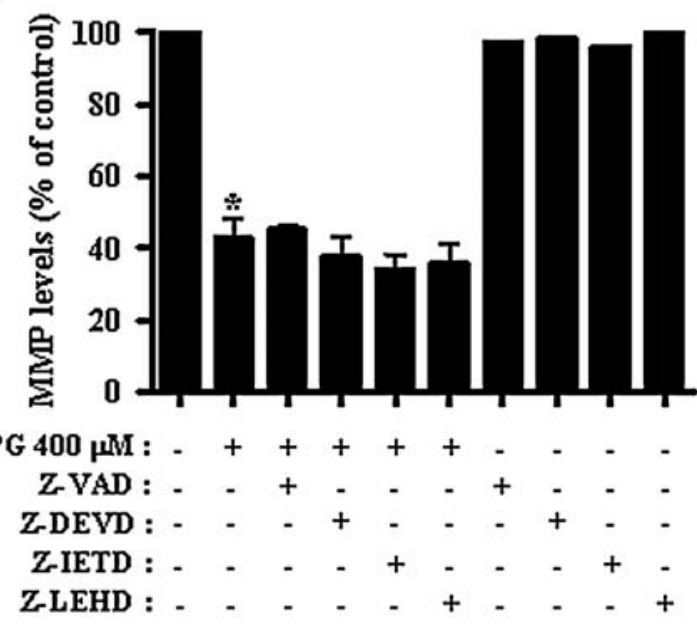

Figure 4. Effects of caspase inhibitors on MMP $\left(\Delta \Psi_{\mathrm{m}}\right)$ in PG-treated CPAEC. Exponentially-growing cells were treated with $400 \mu \mathrm{M}$ PG and/or each caspase inhibitor $(15 \mu \mathrm{M})$ for $24 \mathrm{~h}$. (A and B) The graphs show the percent of Rhodamine 123 negative [MMP $\left(\Delta \Psi_{\mathrm{m}}\right)$ loss] cells (A) and MMP $\left(\Delta \Psi_{\mathrm{m}}\right)$ levels $(\mathrm{B})$ in CPAEC, as measured with a FACStar flow cytometer. ${ }^{*} \mathrm{P}<0.05$ compared with the control group.

CPAEC. As shown in Fig. 5A, the intracellular ROS (DCF) levels were significantly increased in CPAEC treated with $\mathrm{PG}$ at $24 \mathrm{~h}$. The caspase inhibitors did not significantly change the ROS level in PG-treated CPAEC (Fig. 5A). Only pan-caspase inhibitor slightly increased the level (Fig. 5A). All the caspase inhibitors except caspase-3 inhibitor seemed to increase ROS level in control CPAEC (Fig. 5A). The level of red fluorescence derived from DHE, which reflected $\mathrm{O}_{2}{ }^{\bullet}$ accumulation, was not altered in PG-treated CPAEC at $24 \mathrm{~h}$ (Fig. 5B). All the caspase inhibitors except caspase-9 inhibitor increased $\mathrm{O}_{2}{ }^{\bullet-}$ level in PG-treated CPAEC (Fig. 5B). Treatment with Z-VAD and caspase-9 inhibitor decreased $\mathrm{O}_{2}{ }^{\bullet}$ level in control CPAEC (Fig. 5B).

Next, we analyzed the changes of GSH levels in CPAEC in the presence of PG and/or each caspase inhibitor. Treatment with PG increased the number of GSH depleted cells in CPAEC cells $\sim 36 \%$ compared with PG-untreated control cells (Fig. 5C). The tested caspase inhibitors did not significantly affected GSH depletion in PG-treated CPAEC (Fig. 5C). Furthermore, when CMF (GSH) levels in CPAEC except negative CMF staining cells were assessed, GSH level was decreased in PG-treated CPAEC. While caspase-3 
A

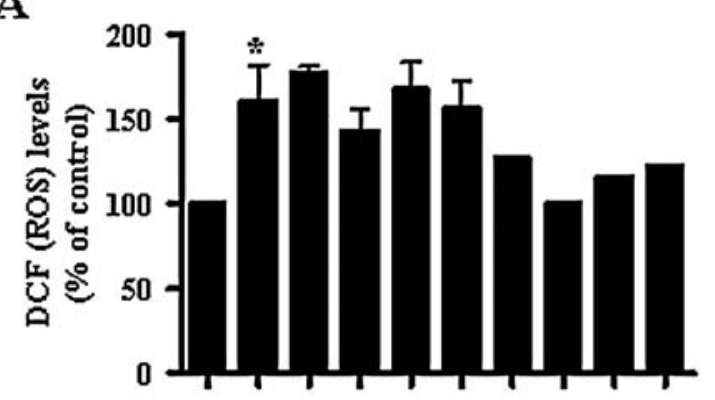

C
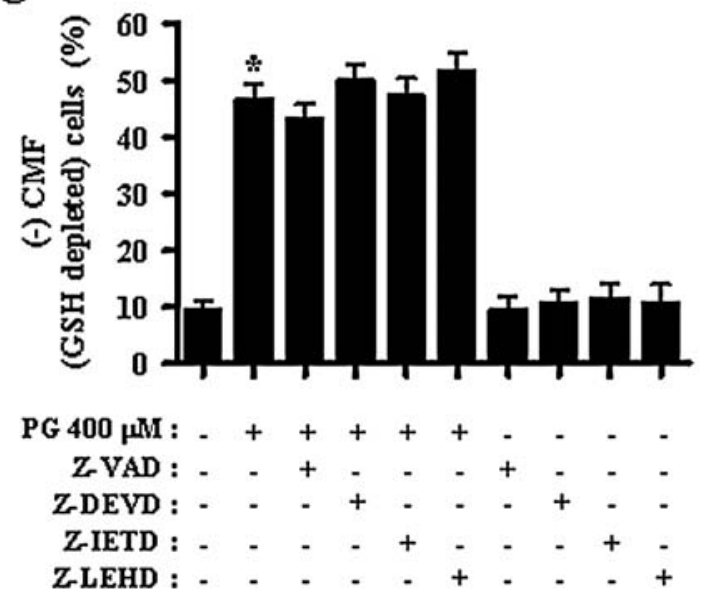

B

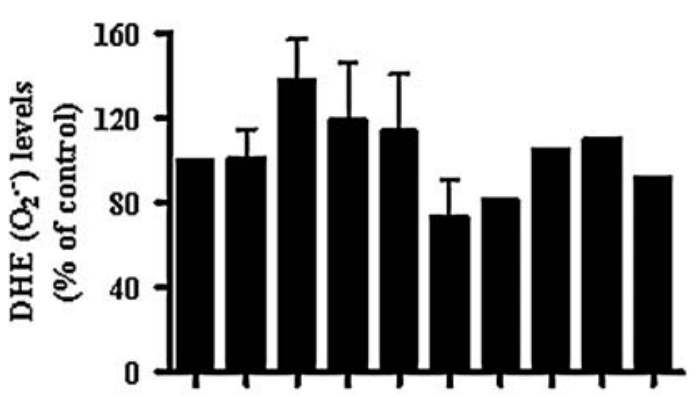

D

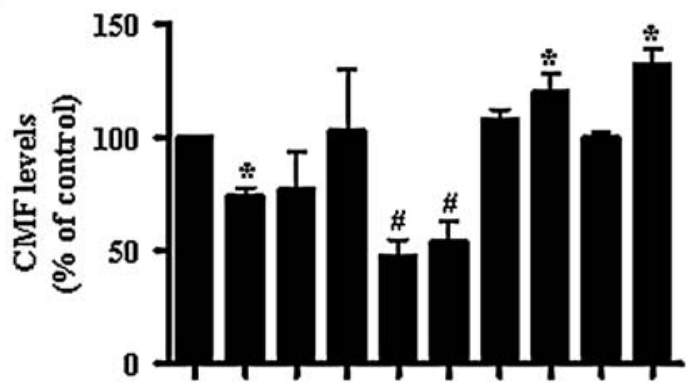

Figure 5. Effects of caspase inhibitors on ROS and GSH levels in PG-treated CPAEC. Exponentially-growing cells were treated with $400 \mu \mathrm{M}$ PG and/or each caspase inhibitor $(15 \mu \mathrm{M})$ for $24 \mathrm{~h}$. ROS and GSH levels in CPAEC were measured using a FACStar flow cytometer. (A and B) Graphs indicate DCF (ROS) levels (\%) compared with control CPAEC at $24 \mathrm{~h}(\mathrm{~A})$ and DHE $\left(\mathrm{O}_{2}{ }^{-}\right)$levels $(\%)$ compared with control CPAEC at $24 \mathrm{~h}(\mathrm{~B})$. (C and D) Graphs show the percent of (-) CMF (GSH depleted) cells (C) and mean CMF (GSH) levels compared with control cells (D). ${ }^{*} \mathrm{P}<0.05$ compared with the control group. ${ }^{\#} \mathrm{P}<0.05$ compared with cells treated with $\mathrm{PG}$ only.

inhibitor increased GSH level in PG-treated CPAEC, caspase- 8 and -9 inhibitors significantly intensified the reduced GSH level (Fig. 5D). All the caspase inhibitors except caspase- 8 inhibitor increased basal GSH level in control CPAEC (Fig. 5D).

\section{Discussion}

In the present study, we focused on evaluating the effects of PG on the growth of endothelial cells, especially CPAEC in relation to apoptosis. PG decreased the population of CPAEC and HUVEC. The ratio of dead cells to viable cells was increased after treatment with PG compared with PGuntreated cells. PG also inhibited the growth of CPAEC and HUVEC in view of an MTT assay. The susceptibility of CPAEC to PG was higher than that of HUVEC. In addition, PG induced apoptosis in CPAEC as evidenced by sub-G1 cells, annexin V staining cells and DNA fragmentation. However, treatment with $400 \mu \mathrm{M} \mathrm{PG}$, which significantly triggered apoptosis in CPAEC, did not increase annexin $\mathrm{V}$ staining cell number in HUVEC (data not shown).

Apoptosis is closely related to the collapse of MMP $\left(\Delta \Psi_{\mathrm{m}}\right)(22)$. It was reported that $\mathrm{PG}$ is cytotoxic to isolated rat hepatocytes because it impairs mitochondria, leading to ATP depletion (12). Correspondingly, PG dose-dependently induced the loss of MMP $\left(\Delta \Psi_{\mathrm{m}}\right)$ and reduced MMP $\left(\Delta \Psi_{\mathrm{m}}\right)$ level in CPAEC. However, PG did not strongly trigger MMP $\left(\Delta \Psi_{\mathrm{m}}\right)$ loss but reduced MMP $\left(\Delta \Psi_{\mathrm{m}}\right)$ level in HUVEC (data not shown). The difference of susceptibility to PG between these endothelial cells is probably due to the different basal activities of mitochondria and antioxidant enzymes in each cell line. In fact, a number of studies have demonstrated that the activities of mitochondria and antioxidant enzymes are quite differentially regulated depending on cell type, tissue origin and species $(23,24)$, and are associated with a susceptibility to apoptosis $(25,26)$. Collectively, our results demonstrate that PG inhibits the growth of endothelial cells, especially CPAEC via apoptosis and $\operatorname{MMP}\left(\Delta \Psi_{\mathrm{m}}\right)$ loss.

To determine which caspases are required for the induction of apoptosis, PG-treated CPAEC were incubated with various caspase inhibitors. Unexpectedly, all the tested caspase inhibitors slightly reduced the growth of PG-treated CPAEC, and some of caspase inhibitors mildly enhanced apoptosis in these cells. All the inhibitors also increased MMP $\left(\Delta \Psi_{\mathrm{m}}\right)$ loss. These data suggest that CPAEC death induced by PG is not dependent on the activation of caspase and can be triggered to some extent via necrosis. In particular, inhibitor of caspase-8, which is related to cell death receptor pathway in apoptosis $(27,28)$, significantly increased annexin-V staining cell numbers in PG-treated CPAEC. The slight 
enhancement of cell death in PG-treated CPAEC by caspase inhibitors probably resulted from the increased necrotic cell death after the hindrance of apoptotic pathway by them. Since we recently observed that all the caspase inhibitors tested in this experiment significantly prevented PG-induced apoptosis in HeLa cells (unpublished data), the requirement of caspase activation for PG-induced apoptosis is dependent on cell types.

PG can play a role as an antioxidant $(4,7,8)$ or a prooxidant $(10,11)$. Increasing evidence suggests that oxidative stress regulates apoptosis of ECs. In fact, $\mathrm{H}_{2} \mathrm{O}_{2}$, tumor necrosis factor- $\alpha$ (TNF- $\alpha)$ and angiotensin II induce EC apoptosis and stimulate the generation of ROS $(29,30)$. According to our results, the intracellular ROS (DCF) levels were significantly increased in CPAEC treated with PG. In contrast, $\mathrm{PG}$ did not increase $\mathrm{O}_{2}{ }^{\bullet-}$ (DHE) levels. These results suggest that PG can affect the levels of different ROS even in the same cell type and also suggest a possibility that ROS changes by PG is involved to some extent in CPAEC death. The caspase inhibitors did not significantly change ROS (DCF) level in PG-treated CPAEC. However, pan-caspase, caspase-3 and -8 inhibitors increased $\mathrm{O}_{2}{ }^{\bullet-}$ level in PG-treated CPAEC whereas caspase-9 inhibitor decreased $\mathrm{O}_{2}{ }^{\bullet-}$ level without preventing apoptosis. Therefore, these data suggest that the changes of ROS levels by each caspase inhibitor are not tightly related to CPAEC death by PG. The exact role of ROS in PG-induced cell death of CPAEC needs to be defined further.

GSH is a main non-protein antioxidant in cells. It is able to eliminate the $\mathrm{O}_{2}{ }^{\bullet-}$ and provide electrons for enzymes such as GSH peroxidase, which reduce $\mathrm{H}_{2} \mathrm{O}_{2}$ to $\mathrm{H}_{2} \mathrm{O}$. It has been reported that the intracellular GSH content has a decisive effect on anticancer drug-induced apoptosis, indicating that apoptotic effects are inversely comparative to GSH content $(31,32)$. Likewise, PG increased GSH depleted cell number and decreased GSH level in CPAEC. All the tested caspase inhibitors did not affect the number in PG-treated CPAEC. This result is probably correlated to the fact that these inhibitors could not prevent CPAEC death. In addition, caspase-3 inhibitor increased GSH level in PG-treated CPAEC whereas caspase- 8 and -9 inhibitors significantly intensified the reduced GSH level. All the caspase inhibitors except caspase- 8 inhibitor increased basal GSH level in control CPAEC. These results suggest that each caspase inhibitor differently regulate intracellular GSH levels.

In conclusion, PG inhibited the growth of endothelial cells, especially CPAEC via caspase-independent apoptosis. PG-induced CPAEC death was accompanied by ROS increase and GSH depletion. Since little is known about the relationship between PG and endothelial cells, our preliminary results provide the first information on the molecular anti-growth mechanisms of PG in ECs.

\section{Acknowledgements}

This study was supported by a grant of the Korea Healthcare Technology R\&D Project, Ministry for Health, Welfare and Family Affairs and Republic of Korea (A084194) and the Korea Research Foundation Grant funded by the Government of the Republic of Korea (MOEHRD).

\section{References}

1. Final report on the amended safety assessment of Propyl Gallate. Int J Toxicol 26 (Suppl 3): 89-118, 2007.

2. Daniel JW: Metabolic aspects of antioxidants and preservatives. Xenobiotica 16: 1073-1078, 1986

3. Dacre JC: Long-term toxicity study of n-propyl gallate in mice. Food Cosmet Toxicol 12: 125-129, 1974.

4. Wu TW, Fung KP, Zeng LH, Wu J and Nakamura H: Propyl gallate as a hepatoprotector in vitro and in vivo. Biochem Pharmacol 48: 419-422, 1994.

5. Rosin MP and Stich HF: Enhancing and inhibiting effects of propyl gallate on carcinogen-induced mutagenesis. J Environ Pathol Toxicol 4: 159-167, 1980.

6. Abdo KM, Huff JE, Haseman JK and Alden CJ: No evidence of carcinogenicity of D-mannitol and propyl gallate in F344 rats or B6C3F1 mice. Food Chem Toxicol 24: 1091-1097, 1986.

7. Reddan JR, Giblin FJ, Sevilla M, Padgaonkar V, Dziedzic DC, Leverenz VR, Misra IC, Chang JS and Pena JT: Propyl gallate is a superoxide dismutase mimic and protects cultured lens epithelial cells from $\mathrm{H}_{2} \mathrm{O}_{2}$ insult. Exp Eye Res 76: 49-59, 2003.

8. Chen $\mathrm{CH}$, Liu TZ, Chen $\mathrm{CH}$, Wong $\mathrm{CH}$, Chen $\mathrm{CH}$, Lu FJ and Chen SC: The efficacy of protective effects of tannic acid, gallic acid, ellagic acid, and propyl gallate against hydrogen peroxideinduced oxidative stress and DNA damages in IMR-90 cells. Mol Nutr Food Res 51: 962-968, 2007.

9. Hirose M, Yada H, Hakoi K, Takahashi S and Ito N: Modification of carcinogenesis by alpha-tocopherol, t-butylhydroquinone, propyl gallate and butylated hydroxytoluene in a rat multi-organ carcinogenesis model. Carcinogenesis 14: 2359-2364, 1993.

10. Kobayashi H, Oikawa S, Hirakawa K and Kawanishi S: Metalmediated oxidative damage to cellular and isolated DNA by gallic acid, a metabolite of antioxidant propyl gallate. Mutat Res 558: 111-120, 2004.

11. Kawanishi S, Oikawa S and Murata M: Evaluation for safety of antioxidant chemopreventive agents. Antioxid Redox Signal 7: $1728-1739,2005$.

12. Nakagawa Y, Nakajima K, Tayama S and Moldeus P: Metabolism and cytotoxicity of propyl gallate in isolated rat hepatocytes: effects of a thiol reductant and an esterase inhibitor. Mol Pharmacol 47: 1021-1027, 1995.

13. Boyd I and Beveridge EG: Relationship between the antibacterial activity towards Escherichia coli NCTC 5933 and the physicochemical properties of some esters of 3,4,5-trihydroxybenzoic acid (Gallic acid). Microbios 24: 173-184, 1979.

14. Miller C, Castonguay A and Teel RW: Modulation of the mutagenicity and metabolism of the tobacco-specific nitrosamine 4-(methylnitrosamino)-1-(3-pyridyl)-1-butanone (NNK) by phenolic compounds. Mutat Res 368: 221-233, 1996.

15. Jacobi H, Eicke B and Witte I: DNA strand break induction and enhanced cytotoxicity of propyl gallate in the presence of copper(II). Free Radic Biol Med 24: 972-978, 1998.

16. Bassenge E: Endothelial function in different organs. Prog Cardiovasc Dis 39: 209-228, 1996.

17. Park WH, Seol JG, Kim ES, Hyun JM, Jung CW, Lee CC, Kim BK and Lee YY: Arsenic trioxide-mediated growth inhibition in MC/CAR myeloma cells via cell cycle arrest in association with induction of cyclin-dependent kinase inhibitor, p21, and apoptosis. Cancer Res 60: 3065-3071, 2000.

18. Han YH, Kim SZ, Kim SH and Park WH: Arsenic trioxide inhibits the growth of Calu- 6 cells via inducing a G2 arrest of the cell cycle and apoptosis accompanied with the depletion of GSH. Cancer Lett 270: 40-55, 2008.

19. Park WH, Park MN, Han YH and Kim SW: Pyrogallol inhibits the growth of gastric cancer SNU-484 cells via induction of apoptosis. Int J Mol Med 22: 263-268, 2008.

20. Han YH, Kim SZ, Kim SH and Park WH: Arsenic trioxide inhibits growth of As4.1 juxtaglomerular cells via cell cycle arrest and caspase-independent apoptosis. Am J Physiol Renal Physiol 293: F511-F520, 2007.

21. Han YH, Kim SZ, Kim SH and Park WH: Pyrogallol as a glutathione depletor induces apoptosis in HeLa cells. Int J Mol Med 21: 721-730, 2008.

22. Yang J, Liu X, Bhalla K, Kim CN, Ibrado AM, Cai J, Peng TI, Jones DP and Wang X: Prevention of apoptosis by Bcl-2: release of cytochrome c from mitochondria blocked. Science 275: 1129-1132, 1997

23. Oberley LW and Oberley TD: Role of antioxidant enzymes in cell immortalization and transformation. Mol Cell Biochem 84: 147-153, 1988. 
24. Yan T, Li S, Jiang X and Oberley LW: Altered levels of primary antioxidant enzymes in progeria skin fibroblasts. Biochem Biophys Res Commun 257: 163-167, 1999.

25. Jia L, Kelsey SM, Grahn MF, Jiang XR and Newland AC: Increased activity and sensitivity of mitochondrial respiratory enzymes to tumor necrosis factor alpha-mediated inhibition is associated with increased cytotoxicity in drug-resistant leukemic cell lines. Blood 87: 2401-2410, 1996.

26. Sharkey SM, Wilson BC, Moorehead R and Singh G: Mitochondrial alterations in photodynamic therapy-resistant cells. Cancer Res 53: 4994-4999, 1993

27. Ashkenazi A and Dixit VM: Death receptors: signaling and modulation. Science 281: 1305-1308, 1998.

28. Budihardjo I, Oliver H, Lutter M, Luo X and Wang X: Biochemical pathways of caspase activation during apoptosis. Annu Rev Cell Dev Biol 15: 269-290, 1999.
29. Hermann C, Zeiher AM and Dimmeler S: Shear stress inhibits $\mathrm{H}_{2} \mathrm{O}_{2}$-induced apoptosis of human endothelial cells by modulation of the glutathione redox cycle and nitric oxide synthase. Arterioscler Thromb Vasc Biol 17: 3588-3592, 1997.

30. Dimmeler S and Zeiher AM: Reactive oxygen species and vascular cell apoptosis in response to angiotensin II and proatherosclerotic factors. Regul Pept 90: 19-25, 2000.

31. Poot M, Teubert H, Rabinovitch PS and Kavanagh TJ: De novo synthesis of glutathione is required for both entry into and progression through the cell cycle. J Cell Physiol 163: 555-560, 1995.

32. Schnelldorfer T, Gansauge S, Gansauge F, Schlosser S, Beger HG and Nussler AK: Glutathione depletion causes cell growth inhibition and enhanced apoptosis in pancreatic cancer cells. Cancer 89: 1440-1447, 2000. 